This item was submitted to Loughborough's Research Repository by the author.

Items in Figshare are protected by copyright, with all rights reserved, unless otherwise indicated.

\title{
Active learning precursors in multidisciplinary large lectures: a longitudinal trial on the effect of imagery in Higher Education lectures
}

\section{PLEASE CITE THE PUBLISHED VERSION}

https://doi.org/10.1080/87567555.2018.1486802

\section{PUBLISHER}

(C) Taylor \& Francis (Routledge)

\section{VERSION}

AM (Accepted Manuscript)

\section{PUBLISHER STATEMENT}

This is an Accepted Manuscript of an article published by Taylor \& Francis in College Teaching on 4 October 2018, available online: http://www.tandfonline.com/10.1080/87567555.2018.1486802.

\section{LICENCE}

CC BY-NC-ND 4.0

\section{REPOSITORY RECORD}

Roberts, David. 2018. "Active Learning Precursors in Multidisciplinary Large Lectures: A Longitudinal Trial on the Effect of Imagery in Higher Education Lectures". figshare. https://hdl.handle.net/2134/33436. 


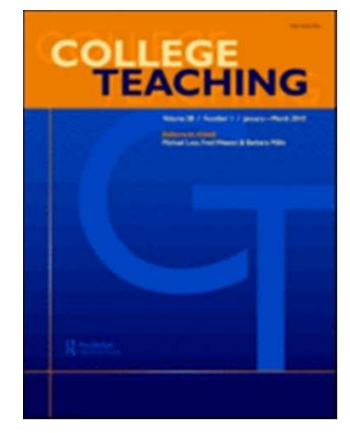

\section{Active learning precursors in multidisciplinary large group lectures: a longitudinal trial on the effect of imagery in Higher Education lectures}

\begin{tabular}{|r|l|}
\hline Journal: & College Teaching \\
\hline Manuscript ID & 24-17-094.R2 \\
\hline Manuscript Type: & Manuscripts \\
\hline Keyword: & $\begin{array}{l}\text { Pedagogy, Multimedia learning, lectures, images, PowerPoint, Visual } \\
\text { learning, Cognitive load theory, active learning, Focus groups, Experiment }\end{array}$ \\
\hline
\end{tabular}


1 Active learning precursors in multidisciplinary large lectures: a 2 longitudinal trial on the effect of imagery in Higher Education 3 lectures

6 College and university teaching involves almost universally and hegemonically the large

7 group lecture format. This ubiquitous learning and teaching space has, however, long

8 been criticized for the production of passive learning in which the 'sage on the stage'

9 transmits and students receive passively. This article reports on and evaluates a

10 longitudinal multidisciplinary controlled experiment in which students were exposed to

11 imagery and non-redundant text-narrative to assess the presence or absence of active

12 learning principles. The trial found that students exposed to MML experienced 40-80\%

13 greater levels of active learning practices over those exposed to narrative and text. Given

14 the physiological (cognitive) nature of MML predictions, the implications of the research

15 impact upon all disciplines where lectures are a means of knowledge-sharing practices in

16 Higher Education. 


\section{Introduction}

32 This article is about the organic production of active learning practices in large group

33 lectures. A key contribution is to demonstrate the unpredicted presence of $\mathrm{AL}$

34 characteristics in MML methods. By 'organic production', I mean that active learning

35 practices in the abstract occur without deliberate intervention to produce them.

36 The intersection of active learning and large group lectures has been treated before in

37 these pages. This work extends and builds upon that and other literature that has evolved

38 in relation to social and technological globalizing forces ascendant since the end of the

39 Cold War. Amongst the earliest, more than twenty years ago, Terry Savage and Karla

40 Vogel (1996: 127) recognized that in conjunction with the rise of computer use in

41 universities, 'the use of different media to convey information' as a departure from the

42 dominance of text in most disciplines implied the potential for an interactivity that

43 challenged the passivity of orthodox monomedia (text only) approaches to teaching. They

44 had spotted the potential that new hardware and software presented for the

45 dissemination in teaching of an expanding array of academic content. It is far more the

46 case now, as the world wide web now connects an almost unending array of resources

47 that digital devices can communicate to student audiences, and that those students can

48 engage and interact with. That potential has been amplified as new software presentation

49 platforms like PowerPoint, Keynote and Prezi allow the merging and projection of multiple

50 media, and professionalize the appearance of such projections. For example, still images,

51 film, documentaries, music and animation can all be integrated into contemporary

52 projection platforms in lecture theatres with relative ease. This article is specifically

53 concerned with the use of full-slide, high quality images used not as an appendage to

54 lecture content offering 'a respite from serious academic work' (Thomas, Place and

55 Hillyard, 2008), but instead as a primary complementary pedagogic medium that

56 enhances text-dominant practices to organically generate active learning practices among

57 students.

58 Early consideration of Multimedia Learning (MML)

59 College Teaching has already engaged with the debate about the use of images and

60 video in teaching. Drawing from Margaret Mackey's research (2003), Elizabeth Thomas et

61 al (2008: 24) grounded their research in the idea that visual images were valuable for

62 'promoting polysemic understanding, or the ability to make sense of texts with multiple

63 channels of information'. This means that a given scholastic tome, dense in text and

64 meaning, may be communicated using media other than just text. Their view (2008: 74) 
65 was that such an approach could serve to 'promote... active learning', and was informed 66 in some part by the work on Multimedia Learning (MML) of Richard Mayer and others.

67 Understandably, given space limitations, the authors could not provide a more thorough

68 exploration of why images might work in such circumstances. Further, their insightful

69 experiment was understandably limited in scope to trials within their own institution over

70 the short-term. For these reasons, although a sound experiment, the data is limited and

71 the explanatory potential constrained. This article proceeds by exploring Multimedia

72 Learning theory in greater depth with a view to considering why images might work well,

73 and examines the wider social context of imagery in the digital era. It will then introduce a

74 longitudinal three-year experiment and the results of control group testing of the effect of

75 images on the organic development of active learning practices among students across

76 nine disciplines at a UK university

77 Before we proceed, however, it's worth considering the nature of hegemonic lecture

78 orthodoxy in Higher Education (HE). At least three elements are apparent. The first is

79 logocentrism. Logocentrism here refers to the privileging of text in HE lectures, above all

80 other media. This pattern is an extension of other scholarly conventions such as the

81 textual character of the books ar 0 urnals from which lectures are often drawn. These in

82 turn are built on the notion that Tanguage constitutes our world, it doesn't just record it

83 or label it. Meaning is always attributed to the object or idea by the human mind, and

84 constructed by and expressed through language (Barry, 2009: 55). Second, our primary

85 delivery platform, PowerPoint, discourages alternatives to text by privileging bullet points

86 and text placeholders when new documents are opened. Although the platform is

87 capable of great media diversity, its default setting encourages the use of text above

88 other media (Adams, 2006). Third, this monopoly perpetuates the legitimacy of the 'sage

89 on the stage', since s/he will monopolise comprehension of scholarly texts and permit

90 their communication in text form only, foreclosing alternative media use that may make

91 knowledge more accessible to student minds. This domination of a particular medium of

92 knowledge communication perpetuates the passive tendency characteristic of HE lectures

93 worldwide (Reinhardt, 1999; Alexander et al., 2002), where there is limited critical

94 interactivity with the academic content of a lecture.

95 It is in this context, of the persistence and hegemony of logocentric lecturing, that we

96 must consider a further aspect of $21^{\text {st }}$ digital life before we consider $M M L$, and this is the

97 rise of the visual. Mitchel (2002) and Felten (2008) both point to a 'pictorial turn' in human

98 evolution brought about by the digitization of photography, the capacity of the web to

99 disseminate digital imagery, and the evolution of computers and software to access,

100 manipulate, catalogue and disseminate digital imagery. The production and consumption

101 of images has never been greater, making our students 'the most visual of all learning 
102 cohorts' (Coats, 2006: 126). Their experiences of communication, engagement, learning

103 and understanding before and after their time with us are shaped extensively by an

104 increasingly visual culture; but their time with us remains dominated by the Gutenberg

105 Press. We operate an eccentrically logocentric lecture system in an increasingly

106 ocularcentric world.

107

108 Multimedia Learning (MML)

109 Multimedia Learning is concerned with the idea that, when presenting content to an

110 audience, a balance of text and images is better for conveying meaning, knowledge and

111 information than text alone (Mayer, 2014). It represents an argument for balance,

112 whereby we balance delivery content between the two key processing channels we

113 possess, as opposed to maintaining an imbalance where we deliver nearly everything

114 down one channel and ignore the other. MML's relevance and importance is connected

115 to our students' inner and outer worlds. By this, I mean that, on the one hand, MML

116 presents cognitive visual capacity as complementary to cognitive audio-textual ability. It

117 considers how our brains process information through our eyes. On the other, MML is

118 particularly suited to the pictorial turn in human evolution, because images are amongst

119 the primary subject of study. Combined, MML demonstrates how our visual capabilities to

120 absorb knowledge can be enhanced by communication with apposite images, as distinct

121 from forms of graphic representation that titillate more than teach (Sung and Mayer,

122 2012). It argues that human beings are dual processors of information (Mayer, 2014;

123 Mayer and Sims, 1994) who interrogate the world around them through two channels

124 (Paivio, 1971; Paivio, 2014; Lewis, 2016; Ayres, 2015). One channel processes audio-

125 textual information, while the other processes imagery. From this perspective, it is a

126 falsehood that only a certain proportion of people learns visually. All sighted people do

127 (Mayer and Moreno, 1998; Paivio, 2014; Sorden, 2013)

128

129 The conclusions MML comes to from such understanding are at least twofold. First, using

130 both available cognitive channels presents an opportunity for students to increase their

131 ability to interpret and understand the world around us (Ayres, 2015; Beetham and

132 Sharpe, 2013). Second, continuing only to use one is by default harmful, because it

133 underutilises some of our learning mechanisms. So, adding images enhances interpretive

134 potential, whilst continuing to depend on text alone or primarily underexploits our

135 capacity to understand. Each channel has limited capacity, both of which can be

136 overloaded, preventing students from processing excessive data. Presently, one is

137 overloaded while the other is underused (Paivio, 2014; Sorden, 2013). MML literature

138 makes the case that persisting in using text the way we do overloads our students' ability 
139 to process the content we are giving them, the way we give it - on PowerPoint slides full 140 of text and bullet points (Lewis, 2016; Mayer and Moreno, 2003; Sweller and Chandler,

141 1991). MML literature posits that, because cognitive loading is better balanced when a

142 combination of images and text are used, audiences will experience higher levels of

143 engagement with academic content.

144

145 We tested and confirmed this proposition but the qualitative methods used to

146 complement the quantitative investigation revealed an unanticipated outcome: the

147 presence of organically-generated active learning processes. By this, I mean that data

148 from the qualitative focus groups we used revealed that the use of images in large group

149 lectures was prompting student interrogation of visual academic content, drawing on pre-

150 existing knowledge to generate new meaning, understanding and conclusions. In the

151 words of David Perkins (1992: 49), students were 'engaging, grappling, and seeking to

152 make sense of things'. This evidence came about incidentally as focus groups created to

153 address questions of engagement identified processes otherwise associated with active

154 learning scholarship, without prompting. These unintentional findings prompted a repeat

155 of the experiment around active learning. The following section outlines how imagery was

156 applied in large group lectures and describes the experiment that evaluated their impact

157 as it relates to the characteristics of active learning. Before this, however, I'll outline what I

158 refer to here as active learning.

159

160 Active Learning

161 A central contribution of this article is to demonstrate the unpredicted presence of $A L$

162 characteristics in MML methods. These are precursors to active learning identified in

163 leading AL literature. It is not suggested as a discussion of learning per se but concerns

164 the agentic activities that are pedagogic necessities for learning to become active. Active

165 Learning $(A L)$ is cast in opposition to the idea of passive learning, in which recipients are

166 'on receive' in an uncritical and inactive mode (Reinhardt, 1999; Harper and Quaye, 2008).

167 In passive learning, knowledge development is unidirectional, controlled by a 'sage on the

168 stage' (McWilliam, 2008). We should be quite careful here. Just because an audience is on

169 'receive' does not mean it is necessarily uncritical and inactive, or that it is pedagogically

170 wasteful. There is an abundance of literature to suggest otherwise (Webster, 2015) (Puttee

171 and Mezzina, 2008; Tokumitsu, 2017). But AL principles in the abstract are specific about

172 the nature of activities students must be engaged with. Glenda Anthony (1996), for

173 example, maintains that learners are engaged in knowledge construction and are conscious of

174 it., building on existing knowledge. Furthermore, that knowledge construction is known to

175 be occurring to the learner. They are conscious of realization. Similarly, Michael Prince 
176 (2004) argues that AL occurs when a student is learning, as opposed to hearing, for

177 example. They will be considering teaching content critically, instead of simply reducing

178 and/or regurgitating what we teach them. For John Savery (2006), an important part of

179 generating such activity is the presence of a problem in need of resolution or

180 transformation, a position also taken by Linda Torp and Sara Sage (2002), Joel Michael

181 (2006) and others (Zepke, 2013; Zepke and Leach, 2010).

182

183 Further, $\mathrm{AL}$ is claimed to occur when learners replace or adapt existing understanding and

184 knowledge with deeper comprehension (Hmelo-Silver, 2004; Stes et al., 2012; von Stumm and

185 Furnham, 2012; Ellis, 2016). Developing AL further, Philippa Levy (2012) maintains that

186 successful inquiry-guided learning (as the interrogative aspect of $A L$ that stimulates

187 transformative learning) is characterised by an interrogative process that pushes students

188 to create their own answers to problems, instead of answers being provided by

189 academics. For Daniel Edelson et al (1999), this means that learners become autonomous

190 agents of discovery who can identify new knowledge, use it to build on their existing

191 knowledge structures, and then use that to solve problems. At the heart of the matter lies

192 the questions that students must find answers to, with guidance: AL requires the injection

193 and stimulation of a process of student inquiry. No absolute prescription is claimed for the

194 form a problem should take; the objective is the stimulation of interrogative inquiry on the

195 part of students (Bradfield, et al., 2015). Summarising, the key characteristics of active

196 learning identified in the abstract by leading scholars concern:

197

198

199

200

201

202

203

204

205

206

207

208

209

210

211

212
- Stimulation of curiosity and a desire to know more

- Provocation of inquiry

- Presentation of problems to be solved

- New knowledge construction from existing foundations of knowledge

The exit survey questions in this study are meant to capture this data. I turn now to the introduction of image-based lectures in operational undergraduate modules in nine disciplines, and their impact on the production of active learning practices over the course of three years.

\section{Development and application of MML}

My subject interests often involve popular social, economic, environmental and political issues. After realizing how compelling the expanding range of advertising for third sector interests had become, and recognising how complex messages were being effectively conveyed in such advertising and marketing campaigns, I began to consider the extent to 
213 which images might be useful in my teaching. Four years ago, I started using in my

214 modules full-slide images taken from the Internet and from my own collection from my

215 field research. These modules are taught in lecture theatres, with students face to face as

216 part of the regular degree curriculum. I began with a handful of images per lecture, each

217 of a minimum $800 \times 600$ pixels (for clarity and quality). I built on this and presently use

218 images in more than 70\% of all lectures in all the modules I teach at all levels in all the

219 disciplines I work in. These include Peace and Conflict Studies, History, Postcolonial

220 Studies, Critical Feminisms, Business Studies, Politics, International Political Economy and

221 International Relations.

222

223 I combine this approach with spreading text content across more slides to reduce

224 cognitive overload, so there is rarely more than one line of text per slide. Remaining text is

225 inserted into the 'notes view' part of PowerPoint, accessible to students through the

226 Virtual Learning Environment but not visible when I present the slides. I developed this

227 method by combining scholarly work on slide design (Kosslyn, 2007; Duarte, 2008) with

228 'real world' work used routinely beyond the academy (Reynolds, 2011; Kawasaki, 2012). I

229 use two categories of image, illustrative and metaphoric, but there is another I have

230 identified as 'paradox' images that present as a problem by, for example, containing

231 seemingly contradictory elements, like the blood on the diamond, below. Some images

232 combine all aspects. I use illustrative images to describe an issue or event. These can be

233 quite straightforward: an Asaro Mudman, unfamiliar to many, can be rendered apparent

234 and thereby provide an anchor for spoken words, recall and text as well as a point of

235 focus for student attention. I use metaphoric images to help students connect with the

236 unfamiliar through pre-existing knowledge. Martin Eppler (2006: 204-205) proposes that

237 visual metaphors 'support learners in connecting what they already know (the properties

238 of the metaphor domain) with new content (the domain unto which the metaphor is

239 being applied)'. According to Edward McQuarrie and David Mick (1999), easily-

240 recognizable metaphorical images prompt complex cognitive processing. Below are some

241 examples of the images I have used, with supporting text 


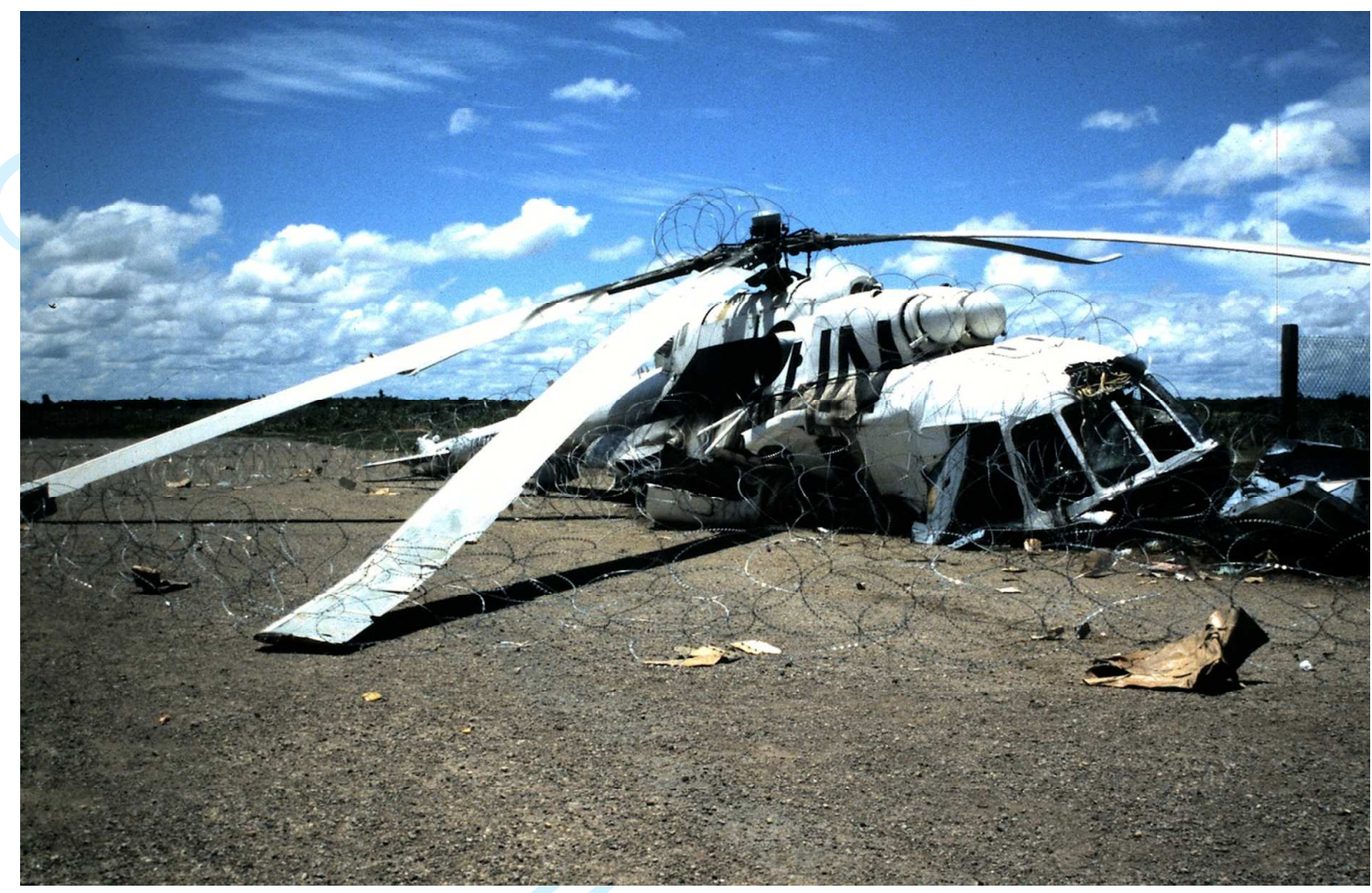

Figure I Crashed UN helicopter, Cambodia, 1993. Copyright of author

244 This illustrative image supported the idea that UN peacekeeping operations normally take 245 place in situations of fragility and complexity. It underpinned a discussion of how fragile 246 peacekeeping interventions can be. 


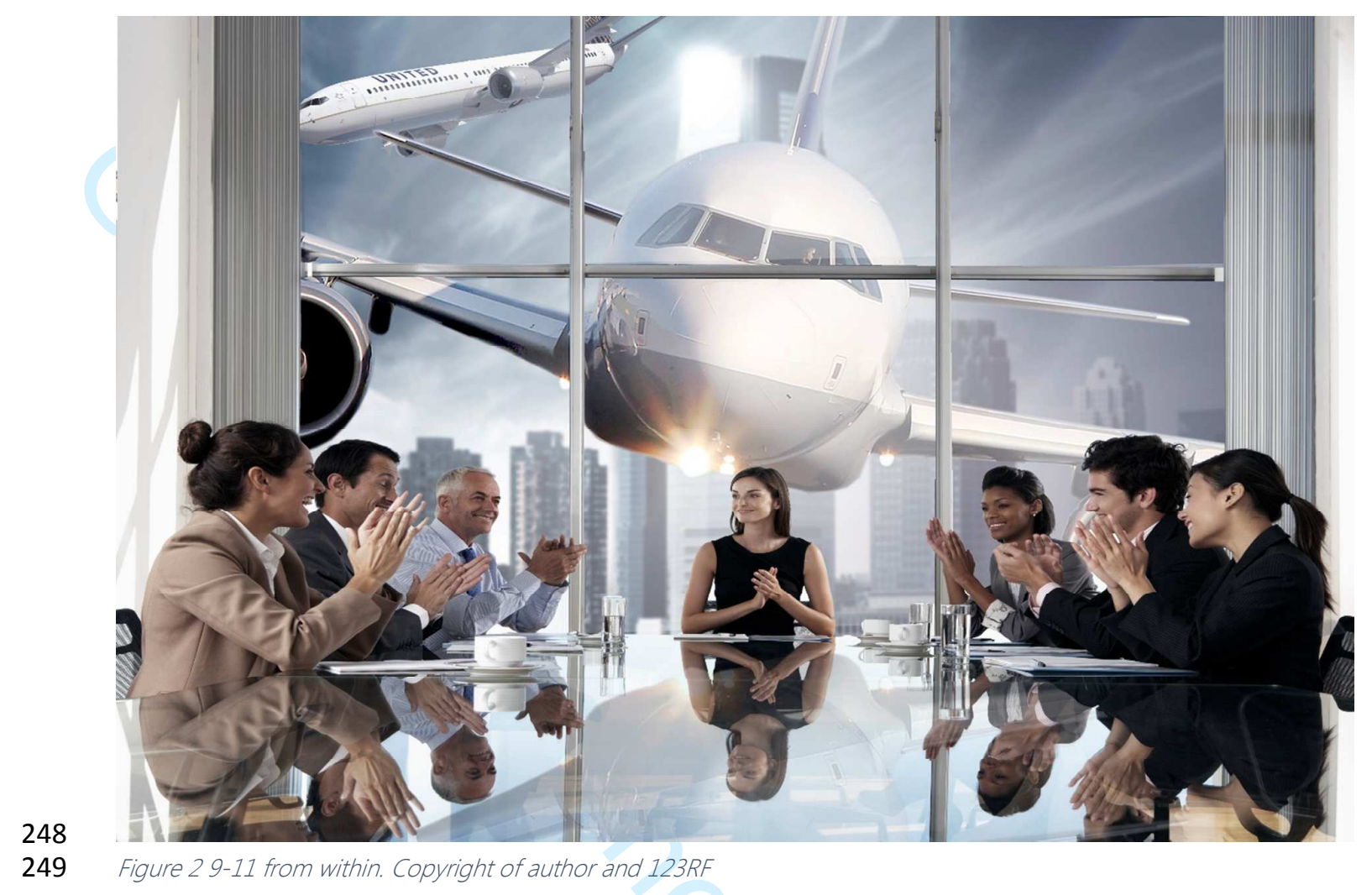

250 This illustrative image describes 9-11 from the inside. It presents a version of events 251 otherwise invisible to the mind 


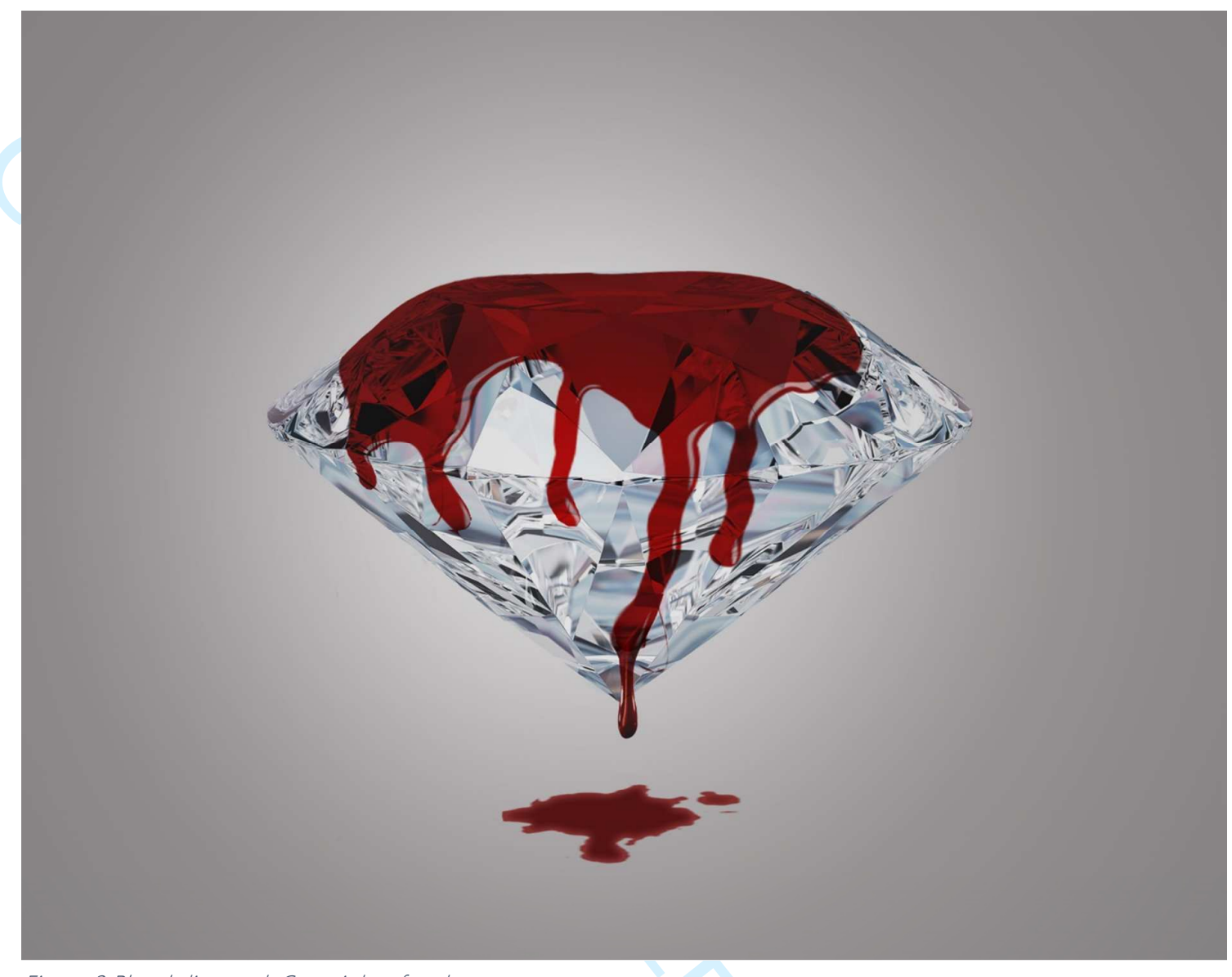

255 This metaphoric image supports several conversations. It has been used to encourage 256 interrogation of capitalism and structural violence (diamond conflict, diamond mining);

257 honour killing, or the murder of a betrothed partner; and domestic violence in the UK and 258 US.

259 
262 This metaphoric image connects the idea of planetary decay to human industrial 263 intervention. 


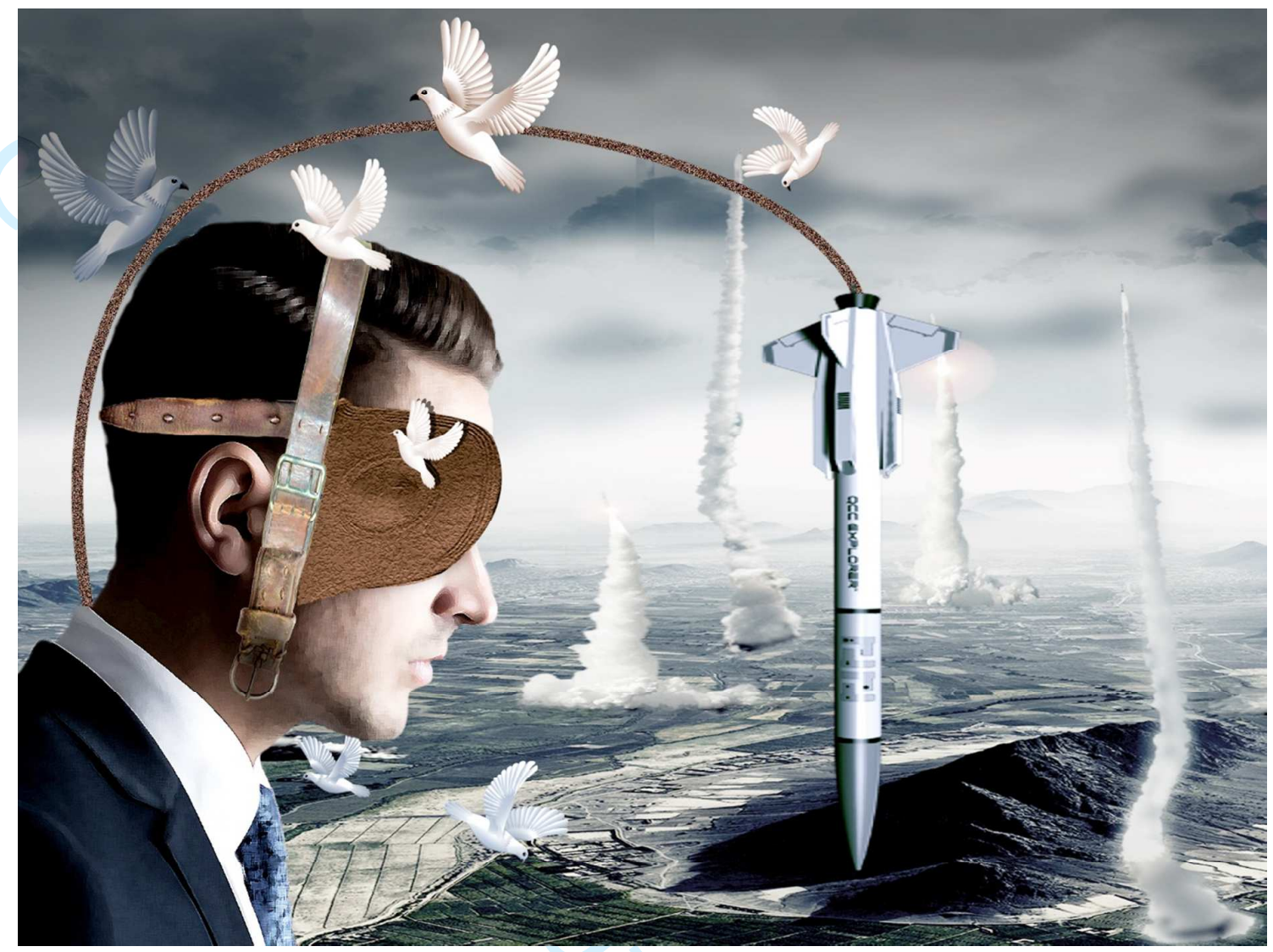

Figure 5 Danger of nuclear weaponry. Copyright of author

267 This metaphoric image helps me talk about the blinkered (hypermasculine) tendency to

268 choose nuclear options every time, regardless of opposition and alternatives (represented

269 by peace doves) all around. It is an example of a more complex visual metaphor

270 illustrating much of the debate in one image. 


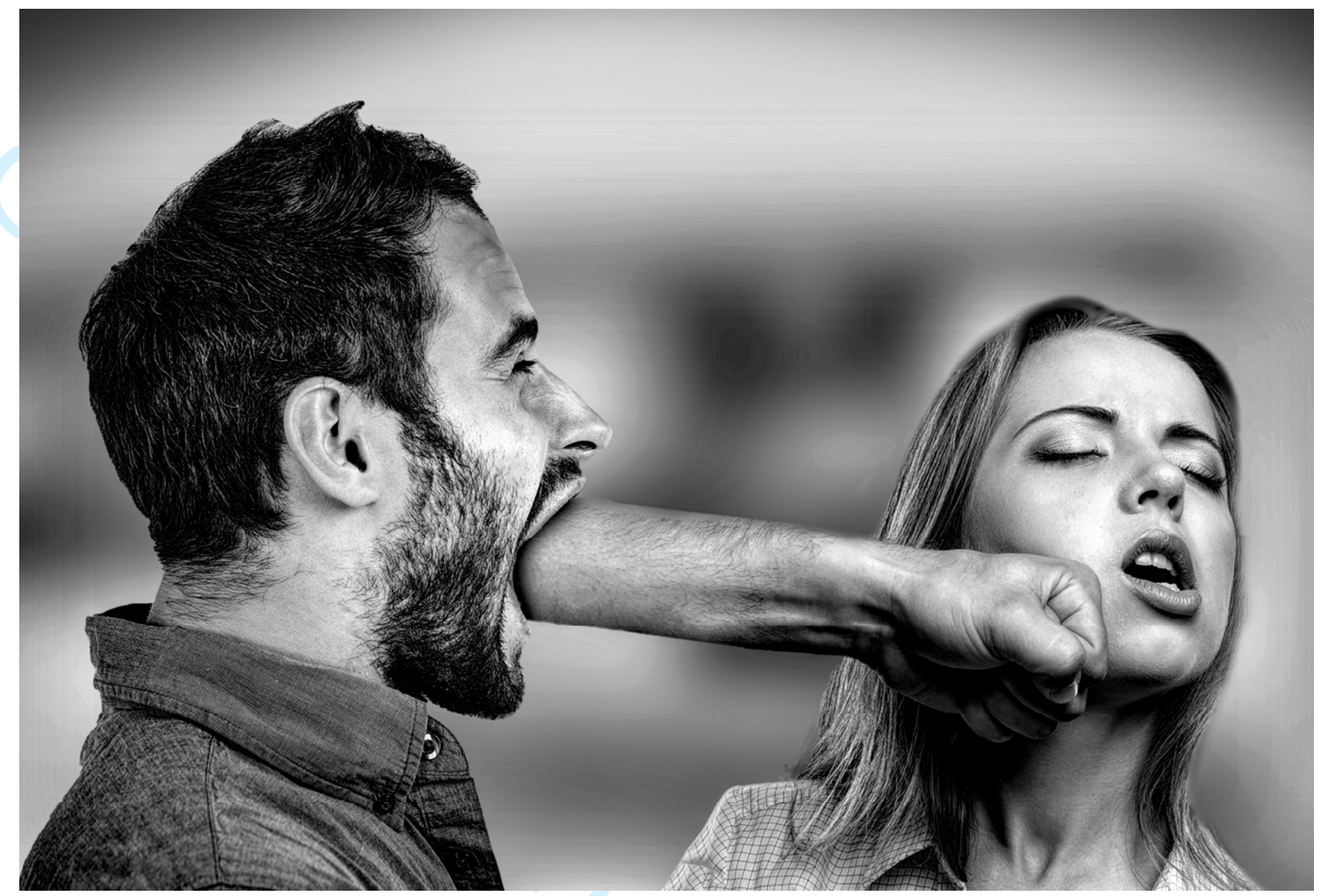

Figure 6 Domestic violence as verbal. Copyright David Roberts/123RF

274 This image helps express the idea that domestic violence can take the form of verbal 275 assault. 


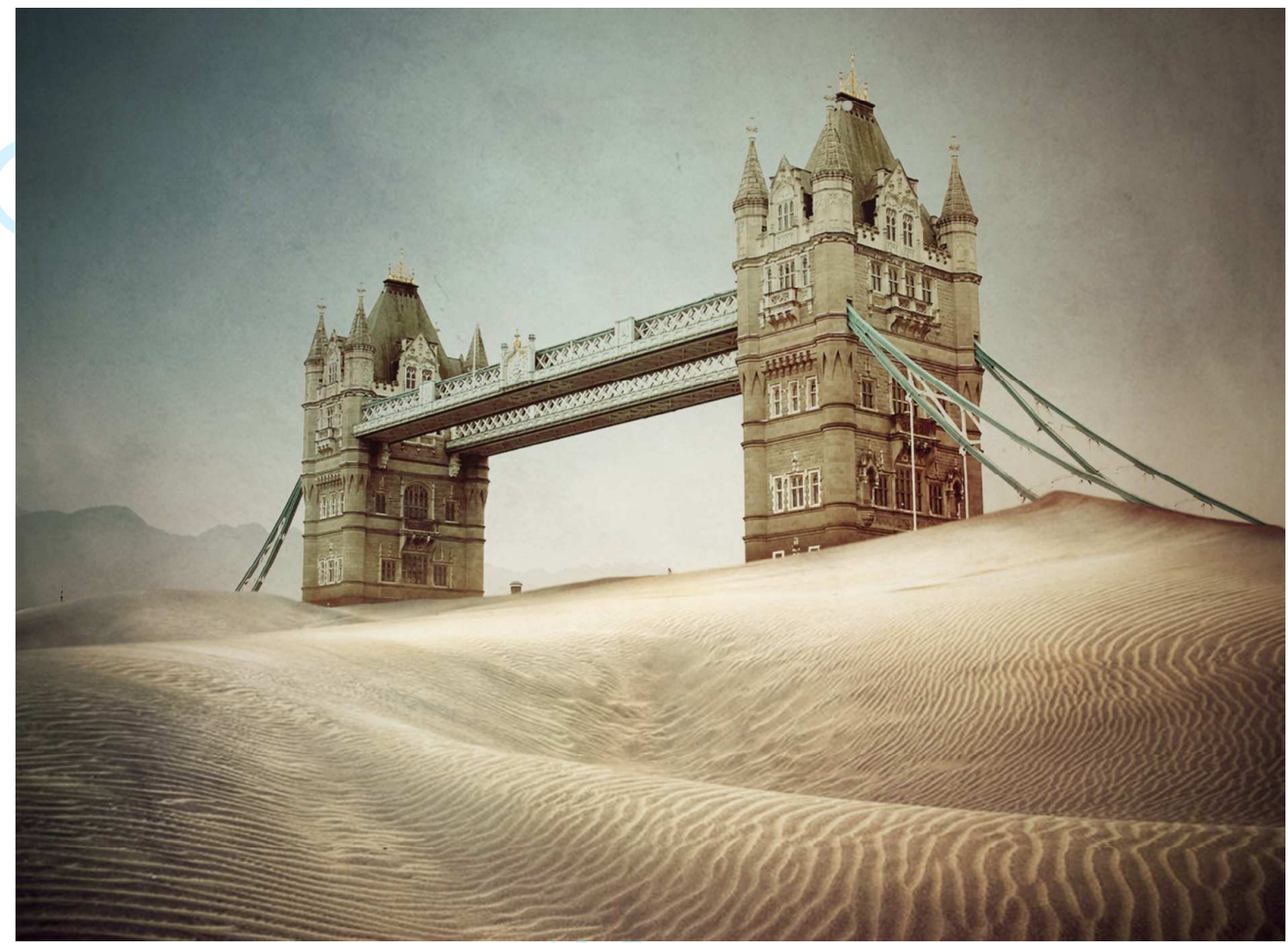

278 Figure 7 Desertification. Copyright David Roberts

279 This is an example of a paradox image. London's Tower Bridge should not be in the 280 middle of sand dunes or a desert. It builds on the familiar and generates conflict that 281 needs to be reconciled. By presenting two elements that should not be simultaneously 282 coterminous, the mind is 'brainjacked' into unscrambling meaning.

\section{Evaluation}

284 Four years ago, I began evaluating this method using control group methods to develop 285 quantitative data and focus groups to develop qualitative data. At the time of this work, 286 Barbara Fenesi et al (2014) were arguing that to further research on MML methods and 287 effectiveness, the best way forward would be to combine controlled experiment 288 methodologies with a 'best practice' approach, using, for example, real course content.

289 This approach was used for the ensuing experiments. It should be noted that several years 290 earlier, Tom Schrand (2008) was proposing this kind of research into the potential of 291 animations and images to generate active learning processes, although he published no 292 further elaborations of his propositions. The quantitative approach chosen bore in mind 293 the proposals of Fenesi et al and Schrand (above), and was adapted from Chanlin (1998), 294 McKay (1999) and Kleinman and Dwyer (1999), who designed control group methods for 295 the assessment of another experiment concerned with images. 
297 The quantitative experiment involved control and test groups numbering 79 students in

298 total. Each group was exposed to one of two 10-minute PowerPoint mini-lectures on

299 global warming. These were separate from the regular curriculum in which the MML

300 method was developed and practiced. The subject of global arming was chosen because

301 it was considered that most participants would have at least some familiarity with the

302 subject through exposure to news media over their lifetimes. It was unlikely to be a

303 subject new to many. Allocation was randomized on the day. The control group watched

304 a PowerPoint presentation using slides with 4-5 bullet points of text. The experiment

305 group watched a PowerPoint presentation that used full-slide images with one line of text

306 chosen to summarise the point of the slide. No additional text in 'notes view' was used,

307 unlike in the regular lectures. Both presentations used identical, recorded narration by this

308 author. Volunteers came from the students taking the regular curricula. All students were

309 under 21 and male volunteers outnumbered females in all sessions. All signed university-

310 supported ethical consent forms. After each presentation, the students individually

311 completed an online exit survey. The survey questions concerned the effect of the slides

312 as opposed to asking about text or images. The experiment has now been placed online

313 participant identities and cohorts as well as survey questions can be adjusted to reflect

314 ongoing research needs. Future participation will be achieved by email invitation and

315 randomization is achieved through embedded code that mutates the URL to each

316 presentation.

317

318 Data from the quantitative experiment, aggregated over the three-year trial, appears in

319 Table 1.

320 [Table 1 here]

321

322

323

324

325

326

327

328

329 The questions asked of students were drawn from the AL literature outlined above, and

330 appear at the bottom of the graph. The darker bars represent students shown slides with

331 text only. The lighter bars represent the responses of students exposed to images and

332 reduced text. The comparative presence of $A L$ characteristics in slides using images and

333 text is substantially greater than in those slides using text alone, and is not predicted in the

334 MML literature. The data are not surprising. Cognitive load is better balanced when 
335 information is bifurcated and distributed more evenly across both audio-textual and visual

336 processing channels. But the reasons for increased presence of AL characteristics are

337 better explored using focus groups. The exit survey data provided information on scale but

338 lacked exploratory and explanatory capacity, 2 focus groups were added to the

339 methodological repertoire to help understand what was happening for students in this

340 process. Focus groups involve 'an in-depth, open-ended group discussion of 1-2 hours'

341 duration that explores a specific set of issues on a predefined and limited topic'

342 (Robinson, 1999, p. 905). For Sue Wilkinson, focus groups encourage 'the production of

343 more fully articulated accounts; and offer an opportunity to observe the process of

344 collective sense-making in action' (Wilkinson, 1998, p. 181; Stewart \& Shamdesani, 2014).

345 They foster an environment in which group members are encouraged to engage with one

346 another. This method continues our adoption of Participatory Action Research (Chevalier

$347 \&$ Buckles, 2013).

348

349

350 The following section distils the findings from six focus groups each consisting of between

351 four and eight undergraduate students from nine disciplines held over the three years of

352 the experiment, totalling in all 33. There was a bias towards those who had been in the

353 experiment group of close to 2:1. Males outnumbered females three to one. I facilitated

354 the groups' discussions with the intention of enabling participants to hold their own

355 conversations around the same questions that were used in the exit survey. Although most of

356 the participants were unfamiliar with the concept of $A L$, when probed, they identified its

357 key characteristics as being elemental to the processes they experienced when engaging

358 with imagery.

359

360 I was particularly interested in ascertaining whether the students felt they were engaged in

361 an interrogative, interpretative and problem-solving exercise. To widespread agreement,

362 one student declared:

363

364

365

366

367

368

369

370

371

372
I start not knowing what the image is. Watching a confusing image makes me want to hear what the lecturer has to say about it. I need to work the image out, whereas if it's just text I'm bored. I don't need to work anything out; I just rewrite what I'm being shown on the slides. Being confused like that keeps you stimulated the whole lecture, especially since we know there will be more images like this and more puzzles to understand. It keeps us on our toes.

One student claimed that 'when you're looking at a picture you're trying to figure out what the artist intended. It's an interpretive process... They grab your attention because you want to know what it is you're looking at'. Thinking about an image that showed human evolution in one 
373 slide, one remarked, to group consensus, that he 'had to map the content, assemble its 374 component parts from what [he] already knew about evolution'. The image 'puzzled at first', then

375 there was 'relief' in understanding its message. There was group agreement when one member 376 declared: 'I didn't even realize what I was doing. I was just in the picture, thinking about it whilst

377 you talked'. This was an interactive process: students were drawn into the image by their

378 unresolved curiosity and then engaged in problem-solving to understand the image's meaning,

379 whilst audio-textual cognitive processing was free to hear the non-redundant (not repeated on

380 the slide in text form) spoken component discussing intellectual content. The images stimulated

381 inquiry and resolution because they were 'illogical', 'irrational', 'wrong', 'surprising', 'perplexing'

382 and 'needed to be reconciled'. They agreed they were 'working the problem'. One student said: 'I

383 really like the problem-solving - what is going on in the image forces you to work it out because it

384 presents a problem'. John Ingledew talks about this as 'brainjacking': the brain is hijacked by the

385 paradox involved (2011: 9). The process seems organically to lead the mind into inquiry. It's worth

386 recording a particular student comment at length. It concerned a student's reflection on an image

387 of a transparent pill containing miniature skulls rather than medicine, because it paints the

388 interrogative journey the student took when viewing it:

389

390

391

392

393

394

395

396

397

398

399

400

401

402

403

404

405

406

407

408

409

410

411

412

413
I see the pill and think health, then I see the skulls and I think - that's not right. I see the pill and have thoughts about health; I see skulls and have thoughts of death. Then I try to link it with what the lecturer is saying, and it completes a circle and brings it to life. I can then understand more about the morality of Big Pharma charging poor people for life-saving medicine or something like that. The confusion the image creates makes me try to reconcile the content, which means I am thinking of explanations myself whilst the lecturer is talking around it. I am asking, why is there an image that's created like that? It goes against what I thought I knew, what I'd been told, what I'd learned before.

This reveals also the student's journey in building on pre-existing knowledge; this was a common theme, where students built on what they knew and made connections across various knowledges, some new and some pre-dating their time at university. One student talked about an image used to support discussion of the Cold War. She noted that the image's 'clash' of elements (two opposing representations of the USSR and the US) challenged what she already brought to the lecture and brought about confusion and a more critical engagement. She said that the 'truth' she had come to the lecture with didn't stand up against the evidence being presented and forced her to think critically about the evidence upon which both views rested. It made her 'half the deal', wherein she wasn't 'just sitting silently on "receive"' but was instead 'working to understand, using my brain to ask questions'. She added that it was 'almost the opposite of a normal lecture'. She declared that with that image, she was no longer 'tied' to copying down lecture content and instead was free to 'bring [her] own brain to the table'; she was 'learning for 
414 [herself] instead of being taught to'. Another commented that, during a regular curriculum lecture,

415 when the lecturer discussed the elements and meaning of an image, it was different from

416 someone telling them what it was. It 'nurtured' the 'process of coming to understand'.

417

418 Images were also considered emotionally impactful. One shows what the last moments before the

419 airliners hit the Twin Towers might have looked like from the inside (figure 2). Participants each

420 year agreed that they were 'blown away' by something they couldn't otherwise see or imagine.

421 They said they could almost feel 'the end' for the victims. It drew their breath and made them

422 'ultra-focussed', 'angry as hell' and 'sad'. They were 'fully connected' to the lecture content and

423 wanted to understand more about why the Towers had been attacked beyond the obvious

424 rhetoric of 'terrorism', They wanted to understand what would motivate a group of people with

425 their own families to go to war with the most powerful country in the world in such a calculated

426 fashion.. Another image prompted laughter, surprise and the need to understand more. This

427 showed Tower Bridge, over the Thames in London, half buried under sand drifts. The subject was

428 desertification. One student declared she 'had no idea [desertification] looked like that. I could

429 understand why it would be seen as a threat to people. It really got my attention because I could

430 see the consequences for the first time. I never thought a picture of sand would impact me so

431 much'. Another image, concerning pollution (figure 5), left an 'indelible' mark on students in the

432 group, prompting one to remark that the image 'says everything about the safety problems of

433 nuclear power stations'. Another said the act of pulling the grenade's pin suggested a 'man-made

434 disaster', easing understanding of the theme of the lecture, which was to outline an introduction

435 to theories of social constructivism. In another session, I referred to the celebrated image of the

436 young Viet Namese girl, Kim Phuc, burned by napalm and an air raid continuing behind her. To

437 agreement, one declared: 'I could understand why people in the south hated the American forces.

438 I understood in that picture why America lost the war. Reading the books on the war became

439 easier'.

440

441 It was also important to get a sense of whether illustrative or metaphoric produced different

442 responses. Broadly speaking, both were valued differently. Illustrative images served two purposes.

443 They described in a complementary fashion a subject enunciated verbally or with text; and they

444 alleviate the 'pain' of slides full of text. Metaphors were 'journeys', 'problems to be solved' and

445 'stimulants' among other things. It is clear from these groups that apposite images that convey

446 relevant description and/or meaning, serve the dual purpose of exploiting students' visual

447 processing capabilities whilst also eliminating the harm of excessive text. Metaphors stimulate $\mathrm{AL}$,

448 including intellectual curiosity, and prompt a co-productive symbiosis between these students and

449 their lecturer. A telling remark has much value: 'most of my lecturers just put text up. I'm instantly

450 bored by text. I'm instantly drawn to a picture. Images up the ante and give me autonomy, make

451 me active in the lecture, instead of text that spoon-feeds me'. The view was unanimous in each

452 focus group in each year. One student put it thus: 'if your brain is engaged enough to be asking,

453 "what is that?", then you are definitely active in the learning process. I'm involved in these lectures.

454 I'm busy'. 
456 Conclusions

457 Anecdotal evidence shows an increase in the number of 'firsts' on my own modules increasing by

45830 percent in the time I have developeo method. In the UK, a 'first' refers to assessment marks

459 of $70 \%$ and above. Student feedback al ways remarks on their enjoyment of this teaching method.

460 'Real w 2 experiences discussed above are unequivocal about the use of images in large group

461 lectures. Although MML scholarship does not predict that the use of apposite images in teaching

462 will provoke AL in large group lectures, lectures using MML methods have been shown to increase

463 the presence of AL characteristics by between 40 and $80 \%$ over slides using text only. Focus group

464 testing has confirmed the presence of key characteristics of $A L$, including problem solving,

465 drawing from previous knowledge and developing new knowledge in conjunction with the

466 lecturer's input.

467

468 The implications are far-reaching, primarily because logocentric lecturing remains the hegemonic

469 norm in HE bodies around the world for many reasons, not least of which is their economic (if not

470 pedagogic) efficiency in a pervasively neoliberal climate. But in addition, the physiological nature

471 of the method, wherein underused cognitive capacity is brought into play and overused

472 processing is given a break, applies in all disciplines for all sighted people. The experiment

473 covered 9 disciplines with no discrimination between disciplines, no deviation between them, and

474 no difference in overall outcomes over the 3-year experiment. But much more importantly, we

475 may argue that AL will work in all disciplines because the discipline is theoretically irrelevant. The

$476 \mathrm{MML}$ method concerns and impacts cognition, not content. They concern physiology that applies

477 to all sighted people who process information through two channels. What goes through the two

478 channels is in some ways irrelevant. It's the existence and possession of the channels themselves

479 that enables and predicts increases in $\mathrm{AL}$, which is why we may reasonably predict benefits for all

480 sighted students regardless of discipline. Indeed, methodologically-speaking we might be better

481 off asking if we could find any disciplines in which AL was not positively affected by MML methods.

482 In other words, using images in a range of disciplines stimulates AL practices organically,

483 transforming traditional passive lecture theatres to spaces of active learning. Active learning is

484 encouraged by the subtraction of excessive visible text (more text can be placed in 'notes view')

485 and the addition of increasingly accessible apposite imagery.

486 There are obvious limitations to this research. One is that all the students came from the same

487 institution, and from the same country/culture, reflecting a narrow demography. Second, they

488 were already familiar with the visual method from lectures they had participated in as part of their

489 regular curricula. Third, it is possible the focus groups captured to some extent students who were

490 already enthused by the method. Fourth, participant numbers were low in each session, although

491 the cumulative effect of longitudinal study in some ways compensates for this. Focus group

492 commentary suggests probably the biggest reason for low participation was that it required them

493 to come onto campus to see the presentations. For this reason, the test is now placed online, with

494 a mutating URL created by one of the students ensuring a random and even distribution between

495 control and experiment group volunteers. There is also a need to extend the research to the 
496 science subjects, mirroring NASA's new visual arts project to make scientific complexity more

497 comprehensible to wider audiences. The means to engage and involve students at other

498 institutions is also needed, to take the research to students at universities reflecting different

499 demographics and, indeed, other countries' higher education systems. For this reason, I instigated

500 a Community of Practice which is now evolving that can connect researchers across the world and

501 support diversification of participants. One other limitation is that so far, this research has only

502 been conducted with one lecturer (or instructor) with implications for replicability; this was a key

503 rationale for creating the CoP so colleagues could test the approach.

504

505 Introducing images and redistributing visible text balances cognitive work load and makes mental

506 processing more efficient, more effective, more engaging and more active in the learning process.

507 Socially, adopting MML methods brings academia more in line with our students' life-world

508 experiences before, during and after their time with us, connecting us to the reality that has

509 evolved beyond our doors. Life has become ultra-visual, but we have presently not. MML theory

510 presents an opportunity to effectively transform that situation.

511

512

513

514

515 
517 References

518 Adams, C. (2006) 'PowerPoint, habits of mind, and classroom culture', Journal of Curriculum

519 studies, vol. 38, no. 4, pp. 389-411.

520 Alexander, J., McDaniel, G.S., Baldwin, M.S. and Money, B.J. (2002) 'Promoting, applying and

521 evaluating problem-based learning in the undergraduate nursing curriculum', Nursing Education

522 Perspective, vol. 23, no. 5, pp. 248-53.

523 Anthony, G. (1996) 'Active Learning in a Constructivist Framework', Educational Studies in

524 Mathematics, vol. 31, no. 4, pp. 349-369.

525 Ayres, P. (2015) 'State-of-the-Art Research into Multimedia Learning: A Commentary on Mayer's

526 Handbook of Multimedia Learning', Applied Cognitive Psychology, vol. 29, no. 4, pp. 631-636.

527 Barry, P. (2009) Beginning theory: an introduction to literary and cultural theory, New York:

528 Manchester University Press.

529 Beetham, H. and Sharpe, R. (2013) Rethinking Pedagogy for a Digital Age: Designing and

530 Delivering E-learning, London: Routledge.

531 Chanlin, L. (1998) 'Animation to teach students of differing knwledge levels', Journal of

532 Instructional Psychology, vol. 25, no. 3, pp. 166-175.

533 Coats, J. (2006) Generational learning styles, River Falls, Wisconsin: LERN.

534 Edelson, D., Gordin, D.N. and Pea, R.D. (1999) 'Addressing the Challenges of Inquiry-Based

535 Learning Through Technology and Curriculum Design', The Journal of the Learning Sciences, vol.

536 8, no. 3-4, pp. 391-450.

537 Ellis, R. (2016) 'Qualitatively different university student experiences of inquiry - associations

538 amongst approaches to inquiry, technologies and perceptions of the learning environment', Active

539 Learning in Higher Education, vol. 17, no. 1, pp. 13-23.

540 Eppler, M. (2006) 'A comparison between concept maps, mind maps, conceptual diagrams, and

541 visual metaphors as complementary tools for knowledge construction and sharing', Information

542 Visualization, vol. 5, no. 3, pp. 202-210.

543 Felten, P. (2008) 'Visual Literacy', Change: The Magazine of Higher Learning, vol. 40, no. 6, pp. 6054464.

545 Fenesi, B., Heisz, J.H., Savage, P.I., Shore, D.I. and Kim, J.A. (2014) 'Combining Best-Practice and

546 Experimental Approaches: Redundancy, Images, and Misperceptions in Multimedia Learning', The

547 Journal of Experimental Education, vol. 88, no. 2, pp. 253-263.

548 Harper, S. and Quaye, S.J. (2008) Student Engagement in Higher Education: Theoretical

549 Perspectives and Practical Approaches for Diverse Populations, London: Routledge. 
550 Hmelo-Silver, C. (2004) 'Problem-Based Learning: What and How Do Students Learn?',

551 Educational Psychology Review, vol. 16, no. 3, pp. 235-266.

552 Kleinman, E. and Dwyer, F.M. (1999) 'Analysis of computerized visual skills: relationships to

553 intellectual skills and achievement', International Journal of Instructional Media, vol. 26, no. 1, pp.

554 53-69.

555 Levy, P. (2012) 'Developing inquiry-guided learning in a research university in the United

556 Kingdom', in Lee, V. Inquiry as a Way of Learning in Undergraduate Education. New Directions for

557 Teaching and Learning, San Francisco, CA: Jossey Bass.

558 Lewis, P. (2016) 'Brain Friendly Teaching—Reducing Learner's Cognitive Load', Academic

559 Radiology, vol. 23, no. 7, pp. 877-880.

560 Mackay, M. (2003) 'Researching new forms of literacy', Reading Research Quarterly, vol. 38, no. 3,

561 pp. 403-407.

562 Mayer, R. (2014) The Cambridge Handbook of Multimedia Learning, $2^{\text {nd }}$ edition, New York:

563 Cambridge University Press.

564 Mayer, R. and Moreno, R. (1998) 'A split-attention effect in multimedia learning: Evidence for dual

565 processing systems in working memory', Journal of Educational Psychology, vol. 90, no. 2, pp.

566 312-320.

567 Mayer, R. and Moreno, M. (2003) 'Nine Ways to Reduce Cognitive Load in Multimedia Learning',

568 Educational Psychologist, vol. 38, no. 1, pp. 43-52.

569 Mayer, R. and Sims, V.K. (1994) 'For whom is a picture worth a thousand words? Extensions of a

570 dual-coding theory of multimedia learning.', Journal of Educational Psychology, vol. 86, no. 3, pp.

$571 \quad 389-401$.

572 McKay, E. (1999) 'An investigation of text-based instructional materials enhanced with graphics',

573 Educational Psychology, vol. 19, no. 3, pp. 323-335.

574 McQuarrie, E. and Mick, D. (1999) 'Visual rhetoric in advertising: Text-interpretive, experimental,

575 and reader-response analyses', Journal of Consumer Research, vol. 26, no. 1, pp. 37-54.

576 McWilliam, E. (2008) 'Unlearning how to teach', Innovations in Education and Teaching

577 International, vol. 45, no. 3, pp. 263-269.

578 Michael, J. (2006) 'Where's the evidence that active learning works?', Advances in Physiology

579 Education, vol. 30, no. 4, pp. 159-167.

580 Mitchell, W. (2002) 'Showing seeing: a critique of visual culture', Journal of Visual Culture, vol. 1,

581 no. 2, pp. 165-181.

582 Paivio, A. (1971) Imagery and verbal processes, New York: Holt, Rinehart, and Winston.

583 Paivio, A. (2014) Mind and Its Evolution: A Dual Coding Theoretical Approach, Oxford: Psychology

584 Press. 
585 Perkins, D. (1992) 'Technology meets constructivism: Do they make a marriage?', in Duffy, T. and

586 Jonassen, D.H. Constructivism and the Technology of Instruction: A Conversation, Hillsdale, NJ:

587 Lawrence Erlbaum.

588 Place, N., Hillyard, C. and Thomas, E. (2008) 'Students and teachers learning to see. Part 2: Using

589 visual images in the college classroom to enhance the social context for learning', College

590 Teaching, vol. 56, no. 2, pp. 74-77.

591 Prince, M. (2004) 'Does Active Learning Work? A Review of the Research', Journal of Engineering

592 Education, vol. 93, no. 3, pp. 223-231.

593 Puttee, C. and Mezzina, K.E. (2008) 'In Defence of the Lecture: Strategies to Assist in Experiences

594 in Accounting Units.', E-Journal of Business Education \& Scholarship, vol. 2, no. 2, pp. 28-38.

595 Reinhardt, L. (1999) 'Confessions of a techno-teacher', College Teaching, vol. 47, no. 2, pp. 48-50.

596 Savage, T. and Vogel, K. (1996) 'Multimedia: a revolution in Higher Education?', College Teaching,

597 vol. 44, no. 4, pp. 127-131.

598 Savery, J. (2006) 'Overview of Problem-based Learning: Definitions and Distinctions', The

599 Interdisciplinary Journal of Problem-based Learning, vol. 1, no. 1, pp. 9-20.

600 Schrand, T. (2008) 'Tapping into active learning and multiple intelligences with interactive

601 multimedia: a low-threshold classroom approach', College Teaching, vol. 56, no. 2, pp. 78-84.

602 Sorden, S.D. (2013) 'Cognitive Theory of Multimedia Learning', in Irby, B., Brown, G. and Lara-

603 Alecio, R. Handbook of Educational Theories, Charlotte: Information Age Publishing Inc.

604 Stes, A., de Maeyer , S., Gijbels, D. and an Petegem, P. (2012) 'Instructional development for

605 teachers in higher education: effects on students' perceptions of the teaching-learning

606 environment', British Journal of Educational Psychology, vol. 82, no. 3, pp. 420-435.

607 Sweller, J. and Chandler, P. (1991) 'Cognitive Load Theory and the Format of Instruction',

608 Cognition and Instruction, vol. 8, no. 4, pp. 293-332.

609 Thomas, E., Place, N. and Hillyard, C. (2008) 'Students and teachers learning to see Part 1: Using

610 Visual Images in the College Classroom to Promote Students' Capacities and Skills', College

611 Teaching, vol. 56, no. 1, pp. 23-27.

612 Tokumitsu, M. (2017) Jacobin, 26 February, [Online], Available:

613 https://www.jacobinmag.com/2017/02/lectures-learning-school-academia-universities-pedagogy/

614 [26 May 2017].

615 Torp, L. and Sage, S. (2002) Problems as possibilities: Problem-based learning for K-16 education,

616 Alexandria, VA: Association for Supervision and Curriculum Development.

617 von Stumm, S. and Furnham, A.F. (2012) 'Learning approaches: Associations with typical

618 intellectual engagement, intelligence and the big five', Personality and Individual Differences, vol.

61953 , no. 5, pp. 720-723. 
620 Webster, R. (2015) 'In defence of the lecture', Australian Journal of Teacher Education, vol. 40, no. 621 10, pp. 85-105.

622 Zepke, N. (2013) 'Threshold concepts and student engagement: Revisiting pedagogical content

623 knowledge', Active Learning in Higher Education, vol. 14, no. 2, pp. 97-107.

624 Zepke, N. and Leach, L. (2010) 'Improving student engagement: Ten proposals for action', Active 625 Learning in Higher Education, vol. 11, no. 3, pp. 167-177.

626

627 